
.

\title{
Behavioural outcomes of housing for domestic dog puppies (Canis lupus familiaris)
}

(1)

Katarzyna Majeckaa, ${ }^{*}$, Magdalena Pąsiekb, Dariusz Pietraszewskic, Carl Smithc,d,e

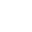

aMuseum of Natural History, Faculty of Biology and Environmental Protection, University of Łódź, Kilińskiego 101, 90-011, Łódź, Poland

bDepartment of Experimental Zoology and Evolutionary Biology, Faculty of Biology and

Environmental Protection, University of Łódź, Banacha 12/16, 90-237, Łódź, Poland

cDepartment of Ecology and Vertebrate Zoology, Faculty of Biology and Environmental Protection, University of Łódź, Banacha 12/16, 90-237, Łódź, Poland

dInstitute of Vertebrate Biology, Academy of Sciences of the Czech Republic, Květná 8, 60365 Brno, Czech Republic

eSchool of Animal, Rural and Environmental Sciences, Nottingham Trent University, Southwell, Nottinghamshire NG25 0QF, UK

*Corresponding author: Katarzyna Majecka,

e-mail: katarzyna.majecka@biol.uni.lodz.pl

phone: + 48426655487

E-mail addresses: magdalena.pasiek@biol.uni.lodz.pl (Magdalena Pąsiek),

dariusz.pietraszewski@biol.uni.lodz.pl (Dariusz Pietraszewski), carl.smith02@ntu.ac.uk (Carl Smith)

Key words: behavioural test, canine, development, kennelling, PAT test, socialization 


\section{Highlights}

- Conditions during sensitive periods of domestic dog puppy development can influence temperament

- We compared two groups of puppies raised under different conditions

- Puppies raised in indoor kennels were more self-confident, but without aggressive tendencies

- Dogs from indoor kennels were better prepared for life among people

(1)

\section{Abstract}

Domestic dogs experience a sensitive period for learning during early life and conditions during this time can have important consequences in the adult. We investigated the effects of kennel environment during early life, comparing the temperaments of puppies reared in indoor kennels, located in the breeder's house, with those reared in outdoor kennels, located outside the breeder's house and with limited human contact. The study was conducted on 264 puppies from 44 litters belonging to 21 breeds. Of these, 160 puppies were reared in indoor kennels (70 female and 90 male puppies, 27 litters) and 104 in outdoor kennels (52 female and 52 male, 17 litters). We conducted PAT (Puppy Aptitude Testing) tests to measure puppy temperament at an age of seven or eight weeks. Using a gamma GLMM fitted using Bayesian inference, we showed a statistically important effect of kennelling on posterior mean PAT scores. Puppies kennelled outdoors scored higher on PAT testing, irrespective of sex or age, and after accommodating for dependency in the data due to litter identity. Puppies raised outdoors showed an elevated tendency for submissive behaviour, a greater risk of aggression through fear, and a lowered capacity for coping with novel conditions. These findings have direct implications for dog breeders and illustrates that enrichment of the environment of dam and puppies can mitigate the risk of behavioural problems in adult dogs. 


\section{Introduction}

Conditions during sensitive periods of early behavioural development in dogs (Canis lupus familiaris) can have profound effects in the adult (Miklósi, 2012). In addition to genetic effects, dog behaviour is modified by experience and environmental conditioning (Lindsay, 2000; Robinson et al., 2016). A sensitive period for learning in domestic dogs starts between 2.5 and 3 weeks and lasts until 12-14 weeks of age (Freedman et al., 1961; Scott and Fuller, 1965). During this period of development environmental enrichment has the greatest potential benefits for puppies. Wells (2004) divided enrichment into two types: animate, deriving from social contacts with conspecifics and humans and inanimate, derived from the provision of toys, cage furniture, and auditory and olfactory stimulation. The first type of enrichment constitutes the process of socialization.

Miklósi (2012) characterized socialization as an epigenetic process whereby an animal learns how to recognise and interact with its group members. Although parents play a central role in socialization, contact with other individuals is also important. In the context of the development of domestic dogs, which are highly sociable, it is an extremely important process. During the socialization period animals must acquire key life skills and engage confidently with their environment (Manning and Dawkins, 1997). In domestic dogs the period of socialization is critical, with experiences at this phase of development having a pronounced influence on the future behaviour of an individual as an adult dog (Kaleta and Fiszdon, 2002; Uzunova et al., 2007; Miklósi, 2012). Because domestic dogs typically occupy environments that are designed primarily for humans, dogs must develop the ability to socialize both with their own species and humans (Bradshaw, 2011). During the sensitive period puppies need the opportunity to experience stressful situations, explore novel environments and engage in problem-solving tasks (Battaglia, 2009; Foyer et al., 2016).

The significance of puppy - human interactions during early life was demonstrated by Freedman et al. (1961) using an experimental approach. Six litters of puppies were isolated from human contact, with five litters permitted human contact for a length of one week between the second and ninth week of life, while the sixth litter received no contact. At the age of 14 weeks, it was demonstrated that the poorest performance was obtained for puppies completely isolated from humans 
as well those exposed to human contact at 2 weeks of age but after exposure to human contact for 2 weeks. Only the litter that received no human contact showed a low desire for human contact. These results imply that a lack of socialization of puppies with humans until the fourteenth week of life cannot be offset at later stages. Given that the socialization process starts from the third week of life, dog breeders play a vital role in proper socialization of puppies. Thus, by providing daily care, hygiene and monitoring contact with their dogs, breeders make a critical contribution to the development of a puppy to their surroundings and the development of a positive relationship with humans (Hubrecht, 1995; Horwitz, 1999; Boxall et al., 2004; Gazzano et al., 2008; Bradshaw, 2011). The term socialization is often used to describe habituation to the physical environment, which is incorrect (Miklósi, 2012). Habituation is a non-associative form of learning characterized by a reduced response to repeated stimulation, expressed as a selective attention process that allows an individual to ignore irrelevant stimuli thereby releasing limited cognitive resources (Ardiel et al., 2017; Schmid et al., 2015). The importance of environmental influences on the outward expression of behaviour in dogs should not be underestimated. Habituating dogs to a range of stimuli in a positive, controlled, and gradual way can help minimize the number of dogs that present undesirable behaviour (Scott and Fuller, 1965; Rooney et al., 2016). Notably the location of a mother and her puppies during early development can have a key influence on the stimuli and learning that puppies receive (Goleman, 2010).

According to some authors, assessing welfare of dogs in kennels is difficult, especially in the context of emotional and psychological wellbeing (Polgar et al., 2019). However, there are a number of features of the kennel environment that might impact on the welfare of dogs, including the space provided and opportunities for environmental and social stimulation. Understanding the impact of these variables is best gained through studies that compare housing systems, though few data are available for comparison (Taylor and Mills, 2007). Here we investigated if the type of housing (outdoor or indoor kennelling) influenced the behavioural disposition of puppies using temperament tests. We predicted that indoor kennelling of puppies, with greater opportunity for socialization, would 
result in better temperament scores in comparison with puppies housed in outdoor kennel facilities, where they would be exposed to fewer human interactions.

Temperament tests can be used as an objective tool for evaluating a variety of social, emotional, cognitive, and motivational dimensions in dogs and several behavioural assays for dogs have been developed (Lindsay, 2001). A commonly used test in 7-8 week-old puppies is Campbell's test. It consists of 5 sub-tests that determine the response of a puppy to a human (Beaudet et al., 1994; Hvozdik et al., 2003). Another assay is the PAT test (Puppy Aptitude Testing), consisting of 10 subtests (Volhard, 2007). The PAT test incorporates tasks included in the Campbell test (Pérez-Guisado et al., 2008) and Puppy Temperament Test (Lindsay, 2001). It also includes an additional three tasks to test responses to touch, sound and the sudden opening of an umbrella. In the present study we employed the PAT test.

\section{Materials and methods}

\subsection{Subjects}

Tests were performed between 2011 and 2018 in Poland using designated breeders belonging to the Fédération Cynologique Internationale (FCI). Breeders were classified into two groups depending on the location of kennelling. Indoor kennels were located in the breeder's house, with the puppies and their mother (dam) having unlimited and continuous access to occupants of the house and exposed to all the stimuli of a typical household. In contrast, outdoor kennels comprised an isolated space for the puppies and dam, located outside the breeder's house, and with human contact limited solely to time when the breeder was engaged in feeding and cleaning. Only small-scale breeders (1-2 breeding bitches) were selected for the study and only breeders recognised by local branches of the FCI as exemplars of good practice. Puppies from large-scale breeders and puppy mills were not included in the study. Puppies from both indoor and outdoor kennels did not leave the household until 7-8 weeks of age. In all cases, puppies and the breeding bitch received a good standard of routine care.

For this investigation a total of 264 puppies from 44 litters belonging to 21 breeds were used. Of these, 160 puppies were reared in indoor kennels (70 female and 90 male puppies, 27 litters) and 104 
in outdoor kennels (52 female and 52 male, 17 litters) (Table 1). Average litter size was $6.0(\mathrm{SE}=0.3)$ and every individual puppy in each litter was tested.

\subsection{Test procedure}

Puppy temperament in response to housing was assessed using the PAT test of Volhard (2007).

Each test comprised 10 subtests. In each subtest, puppies were scored on a scale from 1 to 6 depending on puppy behavioural response (Table 2). In each subtest a score of 1 indicated an individual with aggressive tendencies, or that was hyperactive or independent. Puppies in this category may be difficult to train and would need a competent handler (Bartlett, 1979; Volhard, 2007). A score of 2 suggested self-confidence, but with the possibility that the individual could present aggression. Puppies consistently scoring 3 were judged as tractable and showing relatively stable behaviour with the capacity to adapt to new situations with enthusiasm. A score of 4 indicated a puppy that would be suitable as a pet, but more restrained than these receiving a score of 3. A puppy scoring 4 might need to be shielded from children. A score of 5 signified that a puppy would express distress in novel situations, with the potential to express aggression. Puppies that scored 6 were considered to lack confidence and were expected to show anxiety. These dogs might present aggressive behaviour through fear and would require a stable environment.

PAT tests were conducted on puppies aged either seven or eight weeks old, while they still resided with their breeder. Each puppy was tested individually, in an indoor setting, during daylight (08:00 - 18:00 h), at the breeder's home but in a location unfamiliar to the puppy. Breeding bitches were not present during testing. Puppies were tested prior to their normal feeding time when they were active. All littermates were tested on the same day, with testing for each puppy lasting about 5-6 minutes. All tests were performed by a single tester (one of two female experimenters), who was unknown to the dog under test. The other experimenter (scorer), also unknown to the puppies, behaved neutrally, stayed at the side of the area where the test was carried out, made a video recording of the experiment and noted the results of the subsequent subtests. The final PAT test score assigned to each puppy was agreed jointly by the two experimenters. To assess internal consistency of PAT scoring, 20 
$\%$ of tests, a total of 57 trials, were subsequently scored by a third independent experimenter who observed video footage of trials but was blind to puppy housing treatments. The average inter-score correlation was 0.95 , indicating high correspondence between experimenter and treatment-blind observer.

\subsection{Data analysis}

Data were modelled using R (version 3.5.2; R Development Core Team 2018) with models fitted in a Bayesian framework using Integrated Nested Laplace Approximation (R-INLA; Rue et al., 2017). Mean PAT scores were modelled as a gamma distribution, which assumed scores were continuous and strictly positive. All measured variables were included in the model, which took the form:

$$
\begin{gathered}
P A T_{i j} \sim \operatorname{Gamma}\left(\mu_{i j k}, \phi\right) \\
E\left(P A T_{i j}\right)=\mu_{i j} \text { and } \operatorname{var}\left(P A T_{i j}\right)=\frac{\mu_{i j}^{2}}{\phi} \\
\log \left(\mu_{i j}\right)=\eta_{i j} \\
\eta_{i j}=\beta_{1}+\beta_{2} \times \operatorname{Sex}_{i j}+\beta_{3} \times \text { Age }_{i j}+\beta_{4} \times \text { Kennel }_{i j}+\text { Litter }_{j} \\
\text { Litter }_{j} \sim N\left(0, \sigma_{\text {Litter }}^{2}\right)
\end{gathered}
$$

Where $P A T_{i j}$ is mean PAT score for puppy $i$ belonging to litter $j$, with scores assumed to follow a gamma distribution with mean $\mu$ and precision $\varphi$. Sexij is a categorical covariate corresponding with sex; male and female. The variables Age $i j$ and Kennelij are also categorical covariates, each with two levels, corresponding with age at testing (seven or eight weeks), and kennelling (indoor or outdoor). The random intercept Litter $j_{j}$ was included to introduce a correlation structure between scores for puppies belonging to the same litter, with variance $\sigma_{\text {Litter }}$ distributed normally and equal to 0 .

\subsection{Ethical note}


The study received the approval of The Local Ethics Committee for Animal Experimentation (permit number 5/ŁB732) and was conducted in accordance with rules governing the protection of animals used for scientific purposes.

\section{Results}

There was a statistically important effect of kennelling on posterior mean PAT score (Table 3).

Overall, puppies kennelled outdoors scored higher on PAT testing, irrespective of sex or age, and after accommodating for dependency in the data due to litter identity (Fig. 1). There was no significantly important effect of puppy sex or age on mean PAT score (Table 3). The mean (SD) PAT score for puppies kennelled indoors was $3.16(0.28)$ and outdoors $3.48(0.45)$.

\section{Discussion}

Our results showed statistically important consequences of kennelling conditions for the behavioural temperament of puppies across a broad range of dog breeds. In support of our prediction, puppies raised indoors obtained average scores closer to 3 than puppies from outdoor kennels (Fig. 1). Puppies that achieve PAT scores of 3 can be characterized as self-confident, but without aggressive tendencies and with the capacity to adapt to novel conditions. Scores exceeding 3 show an elevated tendency for submissive behaviour, a greater risk of aggression through fear, and a lowered capacity for coping with novel conditions (Volhard, 2007). Our model does not necessarily imply direct causation between kennelling and PAT score, but only an association. This was particularly the case in the present study since kennelling treatments were self-selected. Notwithstanding this caveat, similar results were obtained by Goleman (2010) who performed tests on German Shepherd puppies kennelled in the breeder's house and in farm kennels. Lenkei et al. (2019) similarly showed differences in preference, recall and gaze test between puppies from outdoor and indoor kennels. An explanation for the association between kennelling on PAT scores observed in our study may be due to quantitative effects, with the 'quality' of the rearing environment driving differences in socialization success. An alternative explanation is that the effects of kennelling arise from qualitative 
differences, with an entirely different habituation process operating in puppies exposed to indoor and outdoor kennelling. In our study, puppies from indoor kennels lived in the breeder's household and from early life were exposed to contact with a larger group of people than those kennelled outdoors. Thus, although puppies from outdoor kennels were also exposed to a wide range of stimuli, those from home breeders experienced an environment more typical of a normal household, to which they would be expected to adapt later in life. The significance of the effects of appropriate stimuli was demonstrated by Pluijmakers et al. (2010) who played audio and visual recordings typical of a household and city environment to puppies. After 3 weeks, puppies expressed greater confidence on contact with novel objects and noises comparing to control groups. This study demonstrates that if puppies receive more varied stimuli during this critical period, the greater the likelihood they will be more confident in the future (Vaterlaws-Whiteside and Hartmann, 2017). Whether the effects we observed resulted from quantitative or qualitative differences will require further research.

Some studies have suggested that human contact is more important than conspecific contact in dogs (Fox, 1986; Wells, 2004; Pullen et al., 2012). Kiddie and Collins (2015) showed that properly housed dogs that experienced frequent contact with their carer achieved better behavioural test results than dogs reared with little psychological and physical stimulation and limited social contact. Similarly, Pettijohn et al. (1977) investigated the reaction of puppies to new sounds, observing that subjects were more confident in the presence of humans than other dogs, food or toys. Moreover, 8week old puppies tested in the presence of a human expressing positive emotional signals towards a stimulus were more likely to approach it than puppies tested with a human expressing neutral emotional signals (Fugazza et al. 2018a). Puppies also showed a greater capacity to learn how to solve a problem with a human demonstrator than with their mother (Fugazza et al. 2018b). Dogs in rescue shelters that experience contact with people also tend to be more sociable and emotionally stable and less fearful (Hennessy et al., 2002). Limiting a dog's opportunity for human social contact may, therefore, undermine successful socialization.

A number of previous studies have shown benefits of socialization in puppies, but also in older dogs. Work by McMillan et al. (2013) showed that dogs bought as puppies from pet stores expressed 
undesirable behaviours as adults, including aggression towards family members, unfamiliar people and other dogs, fear of other dogs, separation anxiety and incontinence. These outcomes contrasted with those for dogs raised by non-commercial breeders. A caveat to this study is that in the case of a well-socialized dog, it is possible that owners may be less likely to relinquish it to a shelter because of behavioural problems.

Work by Gfrerer et al. (2018) testifies to the strong influence of socialization even in mature dogs. Adult Swiss military dogs that were kennelled individually were exposed to conspecifics for three hours each week over an eight-week period. This treatment resulted in a reduction in both offensive and defensive behaviours towards inanimate objects as well as unfamiliar dogs. In contrast, intensive socialization at a later age, after the critical social development period, may fail to eliminate some behavioural problems (Scott and Fuller, 1965). Lack of proper socialization may contribute to future incidences of aggressive behaviour or excessive excitability, among other traits (Battaglia, 2009; Tiira and Lohi, 2015; Garvey et al., 2016).

Our results failed to demonstrate an effect of sex on temperament, contrasting with findings by Wilsson and Sundgren (1998), Svartberg (2002), Ruefenacht et al. (2002), Pérez-Guisado et al. (2008), and Starling et al. (2013), which showed significant differences between male and females. However, other studies have failed to show sex differences in the effects of socialization; e.g. Fuchs et al. (2005), Goleman (2010), and the impact of sex on the environmental effects of early socialization warrants further investigation.

In our study, all breeds were treated as a single species and we did not examine an effect of breed on socialization, or the interaction of breed or breed type with age, sex or treatment. Our reason for ignoring this variable was that our data were not adequately balanced to permit an analysis of this type. In mitigation of this approach, Pullen et al. (2012) showed that dog social responses to strangers or familiar people depended more on environment and past experience than on breed. Moreover, investigation of genetically similar breeds proved that only ancient and spitz breeds differed from others, and only with respect to level of attachment (Tonoike et al. 2015). However, given that artificial selection for specific breeds includes both morphological, physiological and behavioural 
traits, there is a possibility that the success of socialization may vary with breed, and future studies on this question are encouraged.

A potential confounding problem of studies focused on puppy temperament is that differences in behaviour among individuals may arise from a common litter environment as well as from hereditary factors; i.e. from litter effects, (Wilsson and Sundgren, 1998). In the present study we controlled for a litter effect by using a mixed modelling approach, with litter identity included as a random term in our model. Thus, while we identified dependency in our data due to a litter effect, a kennelling effect was still detectable.

\section{Conclusions}

Our results lend support to the hypothesis that early socialization plays a critical role in shaping temperament in dogs, irrespective of age or sex. These findings imply that an environment rich in stimuli, that is typically experienced by a puppy in the home of a breeder, results in a measurably enhanced temperament, better preparing a dog for its subsequent life with an owner. Puppies raised in a home receive exposure to a greater range of physical and social environments, sounds, novel objects and experiences and are more socialized with humans. These findings, and those of comparable studies (Howell et al. 2015), have direct implications for dog breeders, especially those operating outdoor kennels, illustrating that by enriching the environment of dam and puppies, dogs will experience a reduced the risk of subsequent behavioural problems. Our results highlight the critical role breeders can make in preparing puppies, as well as informing future owners, of the importance of socialization and training for companion dogs (Howell et al. 2015).

\section{References}

Ardiel, E.L., Yu, A.J., Giles, A.C., Rankin, C.H., 2017. Habituation as an adaptive shift in response strategy mediated by neuropeptides. NPJ Sci. Learn., 2, 9.

Bartlett, M., 1979. A Novice Looks at Puppy Aptitude Testing. American Kennel Gazette, Pure-Bred Dogs $96,31-42$. 
Battaglia, C.L., 2009. Periods of Early Development and the Effects of Stimulation and Social Experiences in the Canine. J. Vet. Behav. 4, 203-210.

Beaudet, R., Chalifoux, A., Dallaire, A., 1994. Predictive value of activity level and behavioral evaluation on future dominance in puppies. Appl. Anim. Behav. Sci. 40, 273-284.

Boxall, J., Heath, S., Bate, S., Brautigam, J., 2004. Modern concepts of socialization for dogs: implications for their behavior, welfare and use in scientific procedures. Altern. Lab Anim. 32, 81-93. Bradshaw, J., 2011. Dog sense: How the New Science of Dog Behavior Can Make You a Better Friend to Your Pet, Basic Books, New York.

Freedman, D.G., King, J.A., Elliot, O., 1961. Critical period in the social development of dogs. Science, 133, 1016-1017.

Fox, M.W., 1986. Laboratory Animal Husbandry. Ethology: Welfare and Experimental Variables, State University of New York Press, Albany, NY.

Foyer, P., Wilsson, E., Jensen, P., 2016. Levels of maternal care in dogs affect adult offspring temperament. Sci. Rep. 6(1). doi:10.1038/srep19253

Fuchs, T., Gaillard, C., Gebhardt-Henrich, S., Ruefenacht, S., Steiger, A., 2005. External factors and reproducibility of the behaviour test in German shepherd dogs in Switzerland. Appl. Anim. Behav. Sci. 94, 287-301.

Fugazza, C., Moesta, A., Pogany, A., Miklósi, A., 2018a. Presence and lasting effect of social referencing in dog puppies. Anim. Behav. 141, 67-75.

Fugazza, C., Moesta, A., Pogány, Á., Miklósi, Á. 2018b. Social learning from conspecifics and humans in dog puppies. Scientific Reports, 8: 9257. doi: 10.1038/s41598-018-27654-0.

Garvey, M., Stella, J., Croney, C., 2016. Implementing environmental enrichment for dogs. Expert Rev. 13, 1-3.

Gazzano, A., Marit, C., Notari, L., Sighieri, C., McBride, E.A., 2008. Effects of early gentling and early environment on emotional development of puppies. Appl. Anim. Behav. Sci. 110, 294-304. Gfrerer, N., Taborsky, M., Würbel, H., 2018. Benefits of intraspecific social exposure in adult Swiss military dogs. Appl. Anim. Behav. Sci. 201, 54-60. 
Goleman, M., 2010. Impact of sex, age and raising place on puppies' aptitude test results. Rocz. Nauk. Pol. Tow. Zootech. 6, 37-43.

Hennessy, M.B., Voith, V.L., Young, T.L., Hawke, J.L., Centrone, J., McDowell, A., Linden, F., Davenport, G., 2002. Exploring human interaction and diet effects on the behaviour of dogs in a public animal shelter. J. Appl. Anim. Welf. Sci. 5, 253-273.

Horwitz, D., 1999. Counseling pet owners on puppy socialization and establishing leadership. Vet. Med. 94, 149-156.

Howell, T.J., King, T., Bennett ,P.C., 2015. Puppy parties and beyond: the role of early age socialization practices on adult dog behavior. Veterinary Medicine: Research and Reports, 6, 143-153. Hubrecht, R., 1995. Enrichment in puppyhood and its effects on later behavior in dogs. Lab. Anim. Sci. 45, 70-75.

Hvozdik, A., Kottferova, J., da Silva Alberto, J., Ondrasovic, M., 2003. Test of social dominance in dogs. Vet. arhiv 73(4), 237-246.

Kaleta, T., Fiszdon, K., 2002. Wybrane zagadnienia z genetyki i zachowania się psów. SGGW, Warszawa.

Kiddie, J.L., Collins, L.M., 2015. Identifying environmental and management factors that may be associated with the quality of life of kennelled dogs (Canis familiaris). Appl. Anim. Behav. Sci. 167, $43-55$.

Lenkei R, Pogány Á, Fugazza C., 2019. Social behavior in dog puppies: Breed differences and the effect of rearing conditions. Biol. Fut. 70, 134-142.

Lindsay, S.R., 2000. Handbook of Applied Dog Behavior and Training. Vol. 1. Adaptation and learning. Iowa State University Press, Iowa.

Lindsay, S.R., 2001. Handbook of Applied Dog Behavior and Training.. Vol. 2. Etiology and Assessment of Behavior Problems, Iowa State University Press, Iowa.

Manning, A., Dawkins, M.S., 1997. An Introduction to Animal Behaviour. Fourth edition. Cambridge University Press, New York. 
McMillan, F.D., Serpell, J.A., Duffy, D.L., Masaoud, E., Dohoo, I.R., 2013. Differences in behavioral characteristics between dogs obtained as puppies from pet stores and those obtained from noncommercial breeders. J. Am. Vet. Med. Assoc. 242, 1359-1363.

Miklósi, A., 2012. Dog Behaviour, Evolution, and Cognition. Oxford University Press, Oxford. Pérez-Guisado, J., Munoz-Serrano, A., Lopez-Rodriguez, R., 2008. Evaluation of the Campbell test and the influence of age, sex, breed, and coat color on puppy behavioral responses. Can. J.Vet. Res. 72, 269-277.

Pettijohn, T.F., Wong, T.W., Eberg, P.D., Scott, J.P., 1977. Alleviation of separation distress in 3 breeds of young dogs. Dev. Psychobiol. 10(4), 373-381.

Pluijmakers, J.T.M., Appleby, D.L., Bradshaw, J.W.S., 2010. Exposure to video images between 3 and 5 weeks of age decreases neophobia in domestic dogs. Appl. Anim. Behav. Sci. 126, 51-58. Polgar, Z, Blackwell, E., Rooney, N., 2019. Assessing the welfare of kennelled dogs-A review of animal-based measures. App. Anim. Beh. Sci., 213: 1-13. doi.org/10.1016/j.applanim.2019.02.013. Pullen, A.J., Merrill, R.J.N., Bradshaw, J.W.S., 2012. The effect of familiarity on behaviour of kennel housed dogs during interactions with humans. Appl. Anim. Behav. Sci. 137, 66- 73.

Robinson, L.M., Thompson, R.S., Ha, J.C., 2016. Puppy temperament assessments predict breed and American Kennel Club Group but not adult temperament. J. App. Welf. Sci., 19 (2): 101-114 http://dx.doi.org/10.1080/10888705.2015.1127765

Rooney, N.J., Clark, C.C.A., Casey, R.A., 2016. Minimizing fear and anxiety in working dogs: a review. J. Vet. Behav. 16, 53-64.

Rue, H., Riebler, A., Sørbye, S.H., Illian, J.B., Simpson, D.P., Lindgren, F.K., 2017. Bayesian computing with INLA: a review. Ann. Rev. Stat. Applic. 4: 395-421.

Ruefenacht, S., Gebhardt-Henrich, S., Miyake, T., Gaillard, C., 2002. A behaviour test on German Shepherd dogs: heritability of seven different traits. Appl. Anim. Behav. Sci. 79, 113-132.

Schmid, A., Wilson, D.A., Rankin, C.H., 2015. Habituation mechanisms and their importance for cognitive function. Front. Integr. Neurosci. 8(97), 1-2. 
Scott, J.P., Fuller, J.L., 1965. Genetics and the Social Behavior of the Dog. The University of Chicago Press, Chicago.

Starling, M.J., Branson, N., Thomson, P.C., McGreevy, P.D., 2013. Age, sex and reproductive status affect boldness in dogs. The Veterinary Journal, 197: 868-872, doi.org/10.1016/j.tvj1.2013.05.019. Svartberg, K., 2002. Shyness-boldness predicts performance in working dogs. Appl. Anim. Behav. Sci. $79,157-174$.

Taylor, K.D., Mills, D.S., 2007. The effect of the kennel environment on canine welfare: a critical review of experimental studies. Anim. Welf. 16, 435-447.

Tiira, K., Lohi, H., 2015. Early life experiences and exercise associate with canine anxieties PLoS ONE, 10(11), p. e0141907.

Tonoike, A., Nagasawa M., Mogi K., Serpell J.A., Ohtsuki H., Kikusui T., 2015. Comparison of owner-reported behavioral characteristics among genetically clustered breeds of dog (Canis familiaris). Sci. Rep. 5, 17710; doi: 10.1038/srep17710.

Uzunova, K., Stoyanchev, K., Semerdzhiev, V., Rusenov, A., Penchev, I., Kostov, D., 2007. Study on the behaviour of puppies with regard to their socialization. Trakia J. Sci. 5, 12-15.

Varterlaws-Whitesire, H., Hartmann, A., 2017. Improving puppy behavior using a new standardized socialization program. Appl. Anim. Behav. Sci. 197, 55-61.

Volhard, W., 2007. Choosing Your Puppy (PAT). http://www.volhard.com/pages/pat.php (accessed 1 March 2019).

Wells D.L., 2004. A review of environmental enrichment for kennelled dogs, Canis familiaris. Appl. Anim. Behav. Sci. 85, 307-317.

Wilsson, E., Sundgren, P.E., 1998. Behaviour test for eight-week old puppies - heritabilities of tested behaviour traits and its correspondence to later behaviour. Appl. Anim. Behav. Sci. 58, 151-162.

\section{Figure Caption}

Figure 1. Boxplot showing posterior mean PAT scores of male and female puppies at the age of seven and eight weeks exposed to either indoor or outdoor kennelling during early life. 
Fig. 1

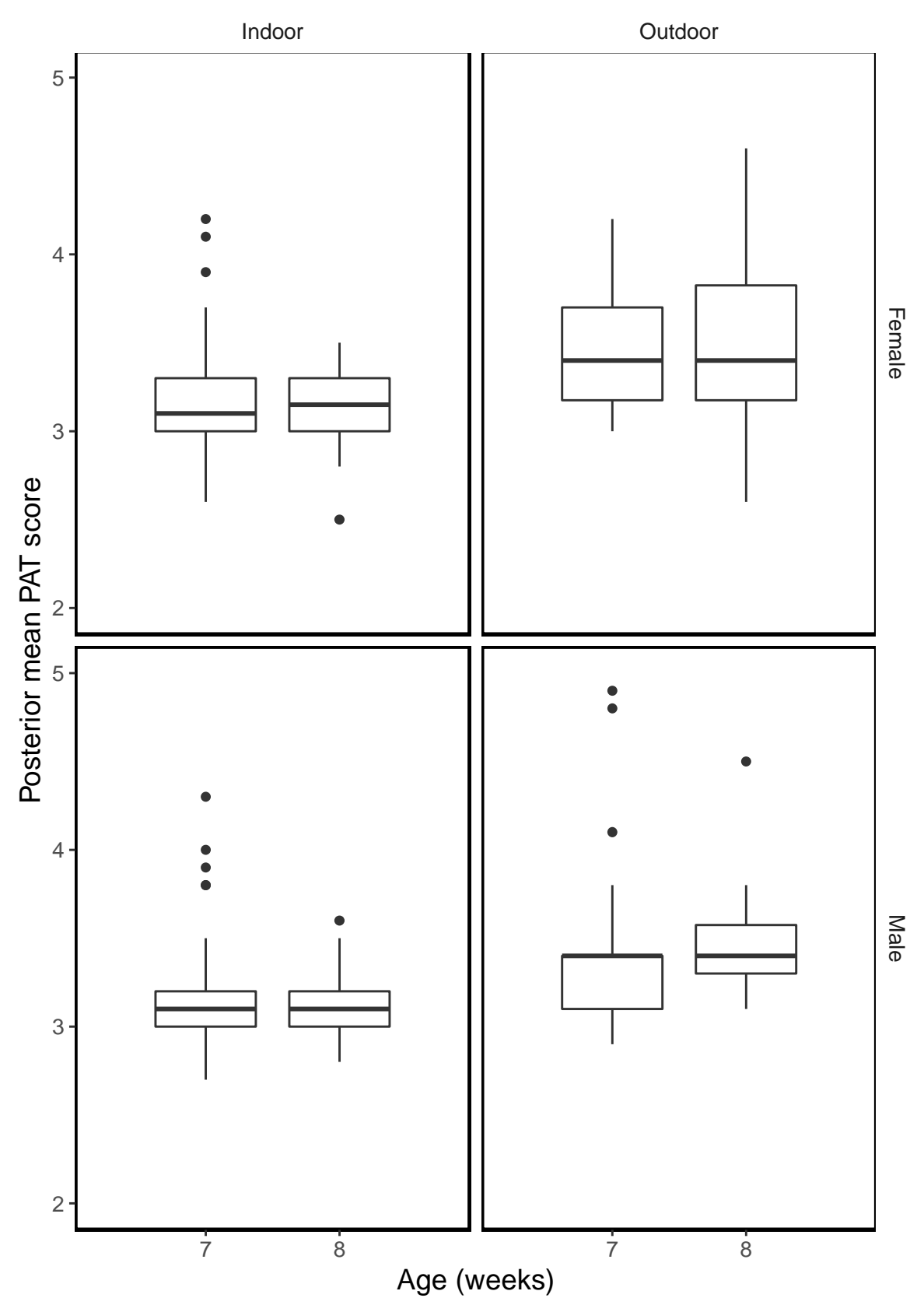


Table 1. Breeds used in the study, kennel location (indoor and outdoor), number of litters and gender of puppies (female and male).

\begin{tabular}{|c|c|c|c|c|c|c|}
\hline \multirow[t]{2}{*}{ Breed } & \multicolumn{3}{|c|}{ Indoor } & \multicolumn{3}{|c|}{ Outdoor } \\
\hline & litters & female & male & litters & female & male \\
\hline American Staffordshire terrier & 1 & 3 & 2 & - & - & - \\
\hline Basset hound & 5 & 9 & 14 & 1 & 6 & 1 \\
\hline Beagle & - & - & - & 1 & 1 & 5 \\
\hline Berger de Beauce & - & - & - & 1 & 5 & 4 \\
\hline Border collie & 1 & 2 & 5 & - & - & - \\
\hline Boxer & 3 & 7 & 9 & - & - & - \\
\hline Bracco Italiano & - & - & - & 1 & 3 & 2 \\
\hline Canaan dog & 1 & - & 4 & - & - & - \\
\hline Central Asian shepherd dog & - & - & - & 1 & 5 & 2 \\
\hline Flat-coated retriever & - & - & - & 2 & 6 & 4 \\
\hline Golden retriever & 2 & 5 & 6 & 2 & 6 & 9 \\
\hline Great Dane & 1 & 9 & 5 & - & - & - \\
\hline Labrador retriever & 2 & 3 & 7 & 1 & 1 & 3 \\
\hline Newfoundland & 1 & 5 & 4 & - & - & - \\
\hline Nova Scotia duck tolling retriever & 4 & 7 & 18 & - & - & - \\
\hline Polish hound & 1 & 3 & 3 & 1 & 6 & 4 \\
\hline Rhodesian ridgeback & 2 & 9 & 6 & - & - & - \\
\hline Samoyed & - & - & - & 1 & 1 & 4 \\
\hline Tatra shepherd dog & 1 & 2 & - & 5 & 12 & 14 \\
\hline Weimaraner & 1 & 5 & 4 & - & - & - \\
\hline Yorkshire terrier & 1 & 1 & 3 & - & - & - \\
\hline Total & 27 & 70 & 90 & 17 & 52 & 52 \\
\hline
\end{tabular}


Table 2. Description of PAT test procedures (modified from Volhard and Volhard, 2007).

\begin{tabular}{|c|c|c|c|}
\hline Subtest & Procedure & Response & score \\
\hline $\begin{array}{l}\text { social attraction } \\
\text { degree of social attraction } \\
\text { to people, confidence or } \\
\text { dependence }\end{array}$ & $\begin{array}{l}\text { Puppy is placed in the test area. Examiner kneels } \\
\text { down and coaxes the puppy to come to them with } \\
\text { encouragement and gently clapping hands. }\end{array}$ & $\begin{array}{l}\text { Came readily, tail up, jumped, bit at hands. } \\
\text { Came readily, tail up, pawed, licked at hands. } \\
\text { Came readily, tail up. } \\
\text { Came readily, tail down. } \\
\text { Came hesitantly, tail down. } \\
\text { Did not come at all }\end{array}$ & $\begin{array}{l}1 \\
2 \\
3 \\
4 \\
5 \\
6\end{array}$ \\
\hline $\begin{array}{l}\text { following } \\
\text { willingness to follow a } \\
\text { person }\end{array}$ & $\begin{array}{l}\text { Examiner stands up and slowly walks away } \\
\text { encouraging the puppy to follow. }\end{array}$ & $\begin{array}{l}\text { Followed readily, tail up, got underfoot, bit at feet. } \\
\text { Followed readily, tail up, got underfoot. } \\
\text { Followed readily, tail up. } \\
\text { Followed readily, tail down. } \\
\text { Followed hesitantly, tail down. } \\
\text { Did not follow or went away. }\end{array}$ & $\begin{array}{l}1 \\
2 \\
3 \\
4 \\
5 \\
6\end{array}$ \\
\hline $\begin{array}{l}\text { restraint } \\
\text { degree of dominance or } \\
\text { submission, ease of } \\
\text { handling in difficult } \\
\text { situations }\end{array}$ & $\begin{array}{l}\text { Examiner reaches and gently places the puppy on its } \\
\text { back and holds it there for } 30 \text { seconds }\end{array}$ & $\begin{array}{l}\text { Struggled fiercely, flailed, bit. } \\
\text { Struggled fiercely, flailed. } \\
\text { Settled, struggled, settled with some eye contact } \\
\text { Struggled, then settled } \\
\text { No struggle } \\
\text { No struggle, avoided eye contact }\end{array}$ & $\begin{array}{l}1 \\
2 \\
3 \\
4 \\
5 \\
6\end{array}$ \\
\hline $\begin{array}{l}\text { social dominance } \\
\text { degree of acceptance of } \\
\text { social dominance by a } \\
\text { person }\end{array}$ & $\begin{array}{l}\text { Let the puppy stand up or sit and gently stroke it from } \\
\text { the head to the back while crouching beside it. }\end{array}$ & $\begin{array}{l}\text { Jumped, pawed, bit, growled. } \\
\text { Jumped, pawed. } \\
\text { Cuddled up to tester and tried to lick face. } \\
\text { Squirmed, licked at hands. } \\
\text { Rolled over, licked at hands. } \\
\text { Went away and stayed away. }\end{array}$ & $\begin{array}{l}1 \\
2 \\
3 \\
4 \\
5 \\
6\end{array}$ \\
\hline $\begin{array}{l}\text { elevation dominance } \\
\text { degree of accepting } \\
\text { dominance while in a } \\
\text { position of no control, such } \\
\text { as at the veterinarian }\end{array}$ & $\begin{array}{l}\text { Examiner covers the puppy with both hands, } \\
\text { supporting the puppy under its chest and gently picks } \\
\text { it up and holds for } 30 \text { seconds. }\end{array}$ & $\begin{array}{l}\text { Struggled fiercely, tried to bite. } \\
\text { Struggled fiercely. } \\
\text { Struggled, settled, struggled, settled. } \\
\text { No struggle, relaxed. } \\
\text { No struggle, body stiff. }\end{array}$ & $\begin{array}{l}1 \\
2 \\
3 \\
4 \\
5\end{array}$ \\
\hline
\end{tabular}




\section{Obedience Aptitude}

\section{retrieving}

degree of willingness to do something for future owner, predisposition for training

\section{touch sensitivity}

degree of sensitivity to

touch and a key indicator to

the type of training

equipment required

\section{sound sensitivity}

degree of sensitivity to

sound, such as loud noises

or thunderstorms

\section{sight sensitivity}

degree of response to a

moving object, such as

chasing bicycles, children

or squirrels

\section{stability}

degree of startle response to

a strange object
The examiner crouched next to the puppy and attracts its attention with a crumpled piece of paper. When

the puppy shows interest, the tester rolls the paper a small distance from the puppy, encouraging it to pick up the paper.

Examiner presses slightly between the index finger and the thumb the ear of the puppy. The tester

gradually increases the pressure, counting to ten and stops when the puppy moves away or shows signs of discomfort.

The puppy is placed in the center of the testing area and the tester, stationed at the perimeter, makes a sharp noise by rattling coins in a glass bottle.

The puppy is placed in the center of the testing area. Examiner ties a string around a bath towel and jerks it across the floor.

An umbrella is opened close to the puppy and gently placed on the ground.
Chased object, picked it up and ran away.

Chased object, stood over it and did not return.

Chased object, picked it up and returned with it to tester. 3

Chased object and returned without it to tester.

Started to chase object, lost interest.

Does not chase object.

8 -10 count before response.

6-8 count before response.

5-6 count before response.

3-5 count before response.

2-3 count before response.

1-2 count before response.

Listened, located sound and ran toward it barking.

Listened, located sound and walked slowly toward it.

Listened, located sound and showed curiosity.

Listened and located sound.

Cringed, backed off and hid behind tester.

Ignored sound and showed no curiosity.

Looked, attacked and bite object.

Looked and put feet on object and put mouth on it

Looked with curiosity and attempted to investigate, tail up.

Looked with curiosity, tail down.

Ran away or hid behind tester.

Hid behind tester.

Looked and ran to umbrella, mouthing or biting it.

Looked and walked to umbrella, smelling it cautiously.

Looked and went to investigate.

Sat and looked but did not move toward the umbrella. 
Showed little or no interest.

Ran away from the umbrella. 
Table 3. Posterior mean PAT score of puppies modelled using a gamma GLMM fitted with INLA with litter identity included as a random term. CrI is the $95 \%$ Bayesian credible interval. Credible intervals that do not contain zero in bold to indicate statistical importance.

\begin{tabular}{lccc} 
Model parameter & Posterior mean & Lower CrI & Upper CrI \\
\hline Intercept & $\mathbf{1 . 1 5 5}$ & $\mathbf{1 . 1 2 5}$ & $\mathbf{1 . 1 8 5}$ \\
Age(8 months) & 0.002 & -0.036 & 0.039 \\
Sex(Male) & -0.010 & -0.034 & 0.014 \\
& & & \\
Kenneling(Outdoor) & $\mathbf{0 . 0 9 4}$ & $\mathbf{0 . 0 5 7}$ & $\mathbf{0 . 1 3 0}$ \\
\hline
\end{tabular}

